\title{
Empathy and Religious Belief in Japan
}

\section{Tatsunori Ishii $^{\mathrm{a}}$ * and Katsumi Watanabe ${ }^{\mathrm{a}, \mathrm{b}}$}

${ }^{a}$ Faculty of Science and Engineering, Waseda University, Room 407-1, Building 59, 3-41 Okubo, Shinjuku-ku, 169-8555, Tokyo, Japan.

${ }^{\mathrm{b}}$ Art and Design, University of New South Wales, Corner of Oxford St and Greens Rd, Paddington, NSW 2021, Australia.

* Corresponding author: t.ishii1108@gmail.com 


\begin{abstract}
:
The exploration of personality factors to explain individual differences in religiosity has demonstrated a link between empathic concern and religious beliefs. Research in the cognitive science of religion has shown a similar link, emphasizing the role of mentalizing (the ability to understand the mental state of others) in formation of religious belief. The current study was designed to compare the effect of two representative measures of empathy, the Empathy Quotient (EQ) and the Empathic Concern subscale of the Interpersonal Reactivity Index (IRI-EC) on religious belief. Study 1 aimed to statistically evaluate the effect of the EQ and the IRI-EC on religious belief with four Japanese samples $(\mathrm{Ns}=207,155,208,183)$. The result of the mini meta-analysis with random effect model indicated that the effect size (semi partial correlation, $\left.r_{\mathrm{sp}}\right)$ of the IRI-EC $\left(r_{\mathrm{sp}}=.120,95 \% \mathrm{CI}\right.$ $[.0002, .237])$ was larger than that of the EQ $\left(r_{\mathrm{sp}}=.074,95 \% \mathrm{CI}[-.0001, .147]\right)$. Moreover, these results were confirmed by Study $2(\mathrm{~N}=1440)$. Thus, the present study provided reliable evidence of the link between empathy and religious belief in non-western, educated, -industrialized, -rich, and -democratic (non-WEIRD) samples and suggested that empathic concern plays an essential role in developing religious belief.
\end{abstract}

\title{
Keywords:
}

religious belief, empathy, mentalizing, Empathic Concern, Empathy Quotient, Japanese

\section{Abbreviations:}

Empathy Quotient (EQ)

Interpersonal Reactivity Index- Empathic Concern (IRI-EC)

Western, educated, industrialized, rich, and democratic (WEIRD) 


\section{Introduction}

Religion is a ubiquitous part of human cultures with most societies having some form of religious practices. This is, in part, because religion has functions that help humans survive (e.g., Fincher \& Thornhill, 2012; Terrizzi Jr, Shook, \& Ventis, 2012) and maintain well-being (e.g., Ebert, Gebauer, Talman, \& Rentfrow, 2020; Routledge, Roylance, \& Abeyta, 2017; Steger \& Frazier, 2005). However, there are individual differences in the extent of religiosity, with some individuals being more religious than others. These individual differences in religiosity have received much attention from personality and social psychologists (e.g., Eysenck, 1998), leading to personality being regarded as a significant factor in religiosity.

For example, the classical studies of H. J. Eysenck (e.g., Eysenck, 1975; 1976) found two personality factors (radicalism/conservatism and tough-/tender-mindedness) that explained individual differences in various social attitudes and reported that religious attitudes (e.g., "whether or not do you agree with the divine law?") were strongly related to tender-mindedness but not to radicalism. Subsequent studies have found similar evidence (e.g., Francis \& Katz, 1992; White, Joseph, \& Neil, 1995; Wilde \& Joseph, 1997; Williams \& Francis, 2006). White et al. (1995) asked their adult participants to answer various questionnaires, including the Eysenck Personality Questionnaire and Francis Scale of Attitudes towards Christianity, and found a negative association between psychoticism and religiosity (i.e., loaded on the same principal component). Using the same scales, Williams and Francis (2006) reported partial correlations between personality and religiosity after controlling for gender; religiosity was neither correlated with Extraversion $(r=.01)$ nor Neuroticism $(r=-.08)$, but correlated negatively with Psychoticism $(r=-.22)$. This negative relationship between religiosity and psychoticism was also found with a non-Christian sample (Israeli: Francis \& Katz, 1992; Muslim: Wilde \& Joseph, 1997). 
Recently studies that focused on the "dark" personality (e.g., narcissism, Machiavellianism, psychopathy) have also reported similar results (Aghababaei, Mohammadtabar, \& Saffarinia, 2014; Haddad, Angman, Archer, \& Garcia, 2016; Lilienfeld, Latzman, Watts, Smith, \& Dutton, 2014; Łowicki, \& Zajenkowski, 2017). For instance, people with religious affiliations scored lower in psychopathy measured by the Dark Triad Dirty Dozen (Haddad et al., 2016) or Psychopathic Personality InventoryRevised (Lilienfeld et al., 2014) than those with no religious affiliations. Aghababaei et al. (2014) and Łowicki and Zajenkowski (2017) found that intrinsic religious orientation was negatively correlated with the Dark Triad personality, especially Psychopathy and Machiavellianism.

\subsection{Empathy and religious belief}

These findings support the idea that particular personality traits contribute to individual differences in religiosity. However, why is psychoticism or dark personality linked to religiosity? One possibility is that empathy mediates this link (e.g., Eysenck, 1998; Łowicki \& Zajenkowski, 2017). For example, Eysenck (1998) summarized the existing data at the time and concluded that the inverse link between Psychoticism and religiosity reflects "a general lack of concern about the welfare of others" (p. 14). Regarding the dark personality, Jonason and Kroll (2015) examined the relationship between the Dark Triad Dirty Dozen and the Interpersonal Reactivity Index (IRI, Davis, 1983), and found that both Psychopathy and Machiavellianism can be characterized as a lack of empathic concern, which means "other-oriented feelings of sympathy and concern for unfortunate others (Davis, 1983)." Recently, Łowicki and Zajenkowski (2017) showed that the inverse relationships between Psychopathy or Machiavellianism and religiosity 
were mediated by the score of an empathy item (e.g., "I feel others' emotions," "I anticipate the needs of others").

These findings about the relationship between empathy and religiosity can be better understood from the perspective of the cognitive and evolutionary science of religion, which has theorized the role of empathy in the emergence of religious belief. For example, the cultural evolutionary theory of the origins of prosocial religions (Norenzayan et al., 2016) assumed that belief in supernatural agents (i.e., gods, spirits), which is a fundamental part of religiosity, is rooted in human cognitive abilities such as mentalizing, also known as "theory of mind." This ability allows one to impute mental states to others, animals, and even non-living things (Heider \& Simmle, 1944; Premack \& Woodruff, 1978). According to the theory, mentalizing allows people to treat supernatural agents as having human-like mental states and enables people to have imaginary interactions with those agents. Through this process, people come to believe in supernatural agents. Importantly, empathy has been considered as one of the core aspects of mentalizing (e.g., Apperly, 2012; Baron-Cohen \& Wheelwright, 2004). Hence, the relationship between empathy and religiosity (e.g., Łowicki, \& Zajenkowski, 2017) seems logical in terms of the cognitive and evolutionary perspective of religious belief.

Previous studies have successfully demonstrated that the scores of several empathy measures positively predicted individual differences in religious belief. For example, the Empathy Quotient (EQ; Baron-Cohen \& Wheelwright, 2004) was frequently used and was found to be a significant predictor of religious belief in samples that are Western (e.g., Lindeman, Svedholm-Häkkinen, \& Lipsanen, 2015; Norenzayan, Gervais, \& Trzesniewski, 2012; Routledge et al., 2017; Willard \& Norenzayan, 2013), and East Asian (Ishii, 2017). The Empathic Concern subscale of IRI (IRI-EC; “other-oriented" feelings of sympathy and concern for unfortunate others, Davis, 1983) has also been used in several studies (Jack, 
Friedman, Boyatzis, \& Taylor, 2016; Khan, Watson, \& Habib, 2005), demonstrating that the IRI-EC positively predicted religious belief.

\subsection{Present Study}

To further understand the relationship between empathy and religious belief, the present study examined the extent to which these two measures of empathy (the EQ and IRI-EC) explained the individual differences in religious belief.

As discussed, empathy could be the key to understanding the individual differences in religiosity. However, empathy is still a multidimensional construct. For example, BaronCohen and Wheelwright (2004) discussed that empathy (i.e., the EQ) is composed of multiple components, such as an affective component (i.e., "feeling an appropriate emotion triggered by seeing/learning of another's emotion"), a cognitive component (i.e., "understanding and/or predicting what someone else might think, feel, or do"), and sympathy (i.e., "feeling an emotion triggered by seeing/learning of someone else's distress which moves you to want to alleviate their suffering"), although they claimed that these components were strongly entangled with each other. Similarly, Davis (1983) assumed that empathy could be measured by four subscales in IRI: empathic concern (i.e., IRI-EC), personal distress, perspective-taking, and fantasy.

Among these dimensions, sympathy or empathic concern appears to be the most relevant to religious belief, in the light of the established relationship between religiosity and psychoticism or the dark personality. Therefore, although the EQ was designed to measure broader empathic skills and has been widely used and shown to be a predictor of religious belief in the cognitive and evolutionary science literature, the IRI-EC would have more substantial predictive power than the EQ. 
If this is the case, there are implications for the discussion about the cognitive foundations of religious belief; among the broader dimensions of empathy, the otheroriented concern may be much more essential for developing religious belief. In addition to attributing mental states to supernatural agents, being concerned about or caring about the content of such agents' mental states means thinking about them for a longer time, and this would contribute to perceiving such agents as human-like and having imaginary interactions with them.

To the best of our knowledge only a few studies have compared the predictive powers of the EQ and the IRI-EC in terms of religious belief. For example, Jack et al. (2016, study 6) reported that the IRI-EC was a significant predictor of religious belief in their multiple regression model, but the EQ was not. This result is consistent with our hypothesis, though their model included several other variables that were not our focus (e.g., analytic thinking measures, perspective-taking). Hence, the current study was designed to compare the EQ's and the IRI-EC's effect on religious belief.

In Study 1, we collected four independent sample groups to examine the relationship between the two measures of empathy (EQ, IR-EC) and religious belief and assessed the strength of the relationship using the meta-analytic method (i.e., computed the effect sizes of the two empathy measures). Moreover, we confirmed these results in Study 2; wherein, the sample size was determined by power analysis using the effect sizes computed in Study 1. All our samples were Japanese adults. Japan has a different religious culture from Western societies; with a long tradition of Shinto or Buddhist religions and is known as a less religious country. For instance, according to Kavanagh and Jong (2020) who analyzed the data form the World Value Survey, only $10 \%$ of Japanese respondents described themselves as "religious" while the rest reported otherwise $(55 \%$ described as "nonreligious," 22\% “Atheist," and 13\% "Don’t Know”). Similarly, Ishii (2017) reported that 
from 140 participants (undergraduates), only 9 affirmed having faith. Despite this, similar to Western countries, more than half of the Japanese population endorsed broad religious/supernatural beliefs (e.g., Ishii 2017; Kavanagh \& Jong, 2020). In summary, while most Japanese individuals naively believed in supernatural agents, they did not explicitly categorize themselves as religious. This feature is still unique to the Japanese population compared to other cultures. (e.g., Staufenberg, 2016). We believe that our findings with "naïve believers" and non-WEIRD (Western, Educated, Industrialized, Rich, and Democratic) samples would contribute significantly to understanding the relationship between personality and religion.

\section{Study 1}

Study 1 aimed to evaluate how closely the two measures of empathy were tied to religious belief. Four independent samples were collected, and a mini meta-analysis was conducted.

\subsection{Methods}

\subsubsection{Samples}

A power analysis was conducted to determine the sample size. A previous study conducted in Japan (Ishii, 2017) reported the bivariable correlations between the EQ and religious belief were .19-.22. Because the IRI-EC was expected to show a larger correlation with religious belief (e.g., Jack et al., 2016), we calculated the sample size based on the report, using $\mathrm{R}$ with pwr package $(\alpha=.05,1-\beta=.80)$. The results indicated that an optimum

of 158-215 participants were needed. We then recruited the recommended number of participants. 
The first sample was 207 undergraduate students $\left(\mathrm{M}_{\mathrm{age}}=19.04\right.$ years, $\mathrm{SD}_{\mathrm{age}}=1.42$, 85 men, 121 women, one unknown) from Sophia University (Tokyo, Japan). They participated in Study 1 in exchange for course credits in an introductory psychology class in May 2018. The second sample comprised 156 undergraduate students $\left(\mathrm{M}_{\mathrm{age}}=18.96\right.$, $\mathrm{SD}_{\text {age }}=0.61,122$ men, 33 women, one unknown) attending a cognitive science class at Waseda University (Tokyo, Japan) and participated in this study as volunteers in January 2019. The third and fourth samples were collected through a crowdsourcing service (Yahoo! Crowdsourcing) in March and May 2019, respectively. We collected data from 208 adults $\left(\mathrm{M}_{\mathrm{age}}=43.21, \mathrm{SD}_{\mathrm{age}}=9.47,156\right.$ men, 52 women $)$ in the third sample and 185 younger adults $\left(\mathrm{M}_{\mathrm{age}}=25.65, \mathrm{SD}_{\mathrm{age}}=3.50,88 \mathrm{men}, 95\right.$ women, two unknown $)$ in the fourth sample. Although our initial intention was to analyze Samples 1-4 as independent studies, the results of Sample 1 were not replicated in the other three samples (2.2. Results). Thus, leading us to conduct a mini meta-analysis of all samples together to avoid redundancy

\subsubsection{Materials and Procedure}

Similar to Ishii (2017), another Japanese study, we used the 13-item measure of religious belief. This measure consisted of three items measuring "the apotheosis of natural products," which is a subscale of the Animism Scale for Adults (Ikeuchi, 2010), six items testing "belief in spirituality," which is a subscale of the short edition of the Attitudes Toward Paranormal Phenomena Scale (Sakata, Kawakami, \& Koshiro, 2012), and four items from the belief in god measure used in Norenzayan et al. (2012). The original belief in god measure has five items. However, one of them ("I believe in god") was excluded, as a similar item ("I believe in gods and buddhas") was used from belief in spirituality subscale. Some examples of items used are, "I think gods dwell in big trees and rocks that exist in nature" (the apotheosis of natural products), "I believe in gods and buddhas" (belief 
in spirituality), "When I am in trouble, I find myself wanting to ask god for help" (belief in god). All items were rated on a 5-point Likert scale ranging from 1 (strongly disagree) to 5 (strongly agree). The average of the ratings (1-5) for each item was calculated for each participant's religious belief score (Sample 1: $\alpha=.85, \mathrm{M}=3.19, \mathrm{SD}=0.68$; Sample 2: $\alpha$ $=.87, \mathrm{M}=2.87, \mathrm{SD}=0.86$; Sample 3: $\alpha=.92, \mathrm{M}=2.96, \mathrm{SD}=0.85 ;$ Sample 4: $\alpha=.89, \mathrm{M}$ $=2.98, \mathrm{SD}=0.85)$

The 13-item belief in god measure included items that reflect not only a belief in gods but also paranormal belief (e.g., the afterlife, a guardian spirit, and previous life). Although both beliefs can be unified into a broader supernatural belief, which is a core aspect of religious belief (e.g., the supernatural belief scale; Jong, Bluemke, \& Halberstadt, 2013), some differences between these two beliefs in terms of their relationship with empathy have been reported (e.g., Willard \& Norenzayan, 2013). Therefore, in addition to the full 13-item measure, we also conducted analyses using the 5-item belief in god measure (Norenzayan et al., 2012) as a dependent variable although the internal consistency of this measure was sometimes low (see Cronbach's alphas below). An item from the belief in spirituality item ("I believe in gods and buddhas") was employed as a substitute for the excluded one ("I believe in god"). The average of the ratings for the five items was calculated for each participant's 5-item religious belief score (Sample 1: $\alpha=.57, \mathrm{M}=3.32$, $\mathrm{SD}=0.71 ;$ Sample 2: $\alpha=.39, \mathrm{M}=3.02, \mathrm{SD}=0.74 ;$ Sample $3: \alpha=.69, \mathrm{M}=3.05, \mathrm{SD}=$ 0.76; Sample 4: $\alpha=.66, \mathrm{M}=3.02, \mathrm{SD}=0.82)$.

As mentioned, two scales were used to assess individual differences in empathy. The first one was the Japanese version of the short form of the EQ (EQ-short; Wakabayashi, Baron-Cohen, \& Wheelwright, 2006; Wakabayashi et al., 2006). The EQ-short consists of 22 items and employs a 4-point Likert scale ranging from 1 (definitely disagree) to 4 (definitely agree). Sample items were "I can easily tell if someone else wants to enter a 
conversation" and "I find it hard to know what to do in a social situation" (reverse-scored item). Each of the items were given two points if the participants strongly displayed an empathizing response (definitely agree or definitely disagree), and one point if they slightly displayed an empathizing response (agree or disagree). Then, the sum of these points was calculated for a total EQ score (Sample 1: $\alpha=.85, \mathrm{M}=18.32, \mathrm{SD}=7.33$; Sample 2: $\alpha=.84$, $\mathrm{M}=16.35, \mathrm{SD}=7.16$; Sample 3: $\alpha=.91, \mathrm{M}=13.38, \mathrm{SD}=8.02$; Sample 4: $\alpha=.87, \mathrm{M}=$ $14.38, \mathrm{SD}=7.69)$.

The second measure of empathy was the 7-item Empathic Concern subscale of the Japanese version of the Interpersonal Reactivity Index (IRI-EC; Himichi et al., 2017), which had items like "I often have tender, concerned feelings for people less fortunate than me." A 5-point Likert scale was used for the IRC-EC in Samples 1, 3, and 4 and a 7-point Likert scale for Sample 2. There was no specific reason for this difference, additionally, as the IRC-EC was standardized in our analysis, it is unlikely to have affected the results. The average rating of the seven items was calculated for each participant's IRI-EC score (Sample 1: $\alpha=.77, \mathrm{M}=3.47, \mathrm{SD}=0.62$; Sample 2: $\alpha=.72, \mathrm{M}=3.86, \mathrm{SD}=0.90 ;$ Sample 3: $\alpha=.83, \mathrm{M}=3.37, \mathrm{SD}=0.69$; Sample 4: $\alpha=.85, \mathrm{M}=3.35, \mathrm{SD}=0.81$ ).

Participants completed these measures on paper (Sample 1) or on the web (Samples 2, 3, 4; Google Forms) in the following order: religious belief measure, the EQ, the IRIEC. They also provided the demographic information (age and gender) at the beginning of the study (Samples 1, 3, 4) or the end (Sample 2).

\subsection{Results}

Multiple linear regression analyses were used to evaluate the strength of the relationships between the two empathy measures (the EQ and IRI-EC) and religious belief. The EQ score, the IRI-EC score, and the religious belief score were standardized and 
entered into the model. Simultaneously, gender $(0=$ male, $1=$ female $)$ and age (standardized) were also entered as independent variables. Previous studies (e.g., Jack et al., 2016; Norenzayan et al., 2012) demonstrated that being female or being older was associated with having firmer religious beliefs, additionally, gender was associated with empathic response towards others. Hence, the effects of these demographic variables on religious belief should be controlled to evaluate the unique effect of the two empathy measures on religious belief. Therefore, data from participants who reported their gender as "unknown" were excluded from the analysis, including the descriptive statistics (cf. 2.1.2. materials and procedure). We also excluded data from participants whose answers were unreliable (e.g., all of the ratings for each item of each measure were the same). As a result, 18, 4, 15, and $10(8.7 \%$, $2.6 \%, 7.2 \%$, and $5.4 \%$ of data) were excluded from Samples $1-4$, respectively. Descriptive statistics were summarized in Table 1 and the results of analysis in Table 2.

\subsubsection{Sample 1}

Bivariable correlations showed that the 13-item religious belief score (i.e., supernatural and paranormal belief) was neither correlated with the EQ score $(r=.07, p$ $=.331)$ nor the IRI-EC score $(\mathrm{r}=.08, \mathrm{p}=.252)$. The same results were observed when the 5-item religious belief score (i.e., personal belief in gods) was used; no significant correlation with the EQ $(\mathrm{r}=.04, \mathrm{p}=.588)$ and the IRI-EC score $(\mathrm{r}=.03, \mathrm{p}=.669)$ was found. The EQ score was positively correlated with the IRI-EC score $(r=.24, p=.001)$.

In a multiple regression model with gender, age, the EQ score, and the IRI-EC score predicting the 13-item religious belief score, gender was significant $(\beta=.39, \mathrm{SE}=0.15, \mathrm{t}$ $=2.62, \mathrm{p}=.010)$, meaning female religious belief scores were higher than male scores. However, the EQ score $(\beta=.04, \mathrm{SE}=0.07, \mathrm{t}=0.47, \mathrm{p}=.642)$ and the IRI-EC score $(\beta$ $=.06, \mathrm{SE}=0.07, \mathrm{t}=0.74, \mathrm{p}=.462)$, as well as age $(\beta=.07, \mathrm{SE}=0.07, \mathrm{t}=0.92, \mathrm{p}=.358)$ 
were not significant. Similar results were obtained with the 5-item religious belief score as a dependent variable (gender: $\beta=.53, \mathrm{SE}=0.15, \mathrm{t}=3.62, \mathrm{p}<.001$, age: $\beta=-.03, \mathrm{SE}=$ $0.07, \mathrm{t}=-0.48, \mathrm{p}=.635$, the EQ: $\beta=.01, \mathrm{SE}=0.07, \mathrm{t}=0.16, \mathrm{p}=.876$, the IRI-EC: $\beta=$ $-.01, \mathrm{SE}=0.07, \mathrm{t}=-0.09, \mathrm{p}=.932)$. Thus, both empathy measures were not related to religious belief in Sample 1.

\subsubsection{Sample 2}

In Sample 2, the 13-item religious belief score was positively correlated with the EQ score $(r=.20, p=.014)$, but not with the IRI-EC score $(r=.04, p=.605)$. Though the internal consistency was low (.39), a similar pattern was shown with the 5-item religious belief score (EQ score $r=.20, p=.013$; IRI-EC score $r=.05, p=.548)$. The two measures of empathy were positively correlated with each other $(r=.25, \mathrm{p}=.002)$.

In the multiple regression model, the EQ score significantly predicted religious belief $(\beta=.19, \mathrm{SE}=0.09, \mathrm{t}=2.21, \mathrm{p}=.028)$, but gender $(\beta=0.14, \mathrm{SE}=0.20, \mathrm{t}=0.68, \mathrm{p}$ $=.498)$, age $(\beta=-.05, \mathrm{SE}=0.08, \mathrm{t}=-0.55, \mathrm{p}=.580)$, and the IRI-EC score $(\beta=-0.01, \mathrm{SE}$ $=0.08, \mathrm{t}=-0.05, \mathrm{p}=.957)$ were not significant. In the same model using the 5-item religious belief score as dependent variable, the result was similar; the EQ score was the only significant predictor of religious belief $(\beta=.18, \mathrm{SE}=0.09, \mathrm{t}=2.10, \mathrm{p}=.038)$, and not others (gender: $\beta=0.26, \mathrm{SE}=0.20, \mathrm{t}=1.28, \mathrm{p}=.204$, age: $\beta=-.06, \mathrm{SE}=0.08, \mathrm{t}=-$ $0.75, \mathrm{p}=.457$, the IRI-EC: $\beta=.004, \mathrm{SE}=0.08, \mathrm{t}=0.05, \mathrm{p}=.960)$. Thus, the EQ was strongly related to religious belief than the IRI-EC in Sample 2.

\subsubsection{Sample 3}

The 13-item religious belief score was strongly correlated with both the EQ $(r=.18$, $\mathrm{p}=.011)$ and the IRI-EC score $(\mathrm{r}=.33, \mathrm{p}<.001)$. The 5-item belief score showed a similar 
correlation with the EQ $(r=.19, \mathrm{p}=.009)$ and the IRI-EC $(\mathrm{r}=.32, \mathrm{p}<.001)$. The two measures of empathy were positively correlated with each other $(r=.42, p<.001)$.

Multiple regression analysis with the 13 -item religious belief measure revealed that the IRI-EC score was the only significant and positive predictor $(\beta=.30, \mathrm{SE}=0.08, \mathrm{t}=$ $3.98, \mathrm{p}<.001)$, while gender $(\beta=.28, \mathrm{SE}=0.16, \mathrm{t}=1.75, \mathrm{p}=.082)$, age $(\beta=.11, \mathrm{SE}=$ $0.07, \mathrm{t}=1.52, \mathrm{p}=.131)$, and the EQ score $(\beta=.04, \mathrm{SE}=0.08, \mathrm{t}=0.55, \mathrm{p}=.586)$ were not significant. The results for the 5-item measure were almost identical; the IRI-EC score significantly predicted religious belief $(\beta=.28, \mathrm{SE}=0.08, \mathrm{t}=3.63, \mathrm{p}<.001)$, but not the other variables (gender: $\beta=.21, \mathrm{SE}=0.16, \mathrm{t}=1.31, \mathrm{p}=.194$, age: $\beta=.13, \mathrm{SE}=0.07, \mathrm{t}=$ $1.84, \mathrm{p}=.067$, the EQ score: $\beta=.06, \mathrm{SE}=0.08, \mathrm{t}=0.75, \mathrm{p}=.454)$. Unlike in Samples 1 and 2, the IRI-EC, rather than the EQ, was strongly related to religious belief in Sample 3.

\subsubsection{Sample 4}

Both religious belief scores were positively correlated with the EQ score (13-item: $\mathrm{r}=.17, \mathrm{p}=.031,5$-item: $\mathrm{r}=.20, \mathrm{p}=.008)$. They were also correlated with the IRI-EC score (13item: $\mathrm{r}=.22, \mathrm{p}=.003,5$-item: $\mathrm{r}=.27, \mathrm{p}<.001)$. A positive correlation was observed between the EQ and IRI-EC scores $(\mathrm{r}=.45, \mathrm{p}<.001)$.

The regression analysis showed that the IRI-EC significantly predicted the 13 -item religious belief score $(\beta=.17, \mathrm{SE}=0.08, \mathrm{t}=1.99, \mathrm{p}=.049)$, but gender $(\beta=.26, \mathrm{SE}=$ $0.15, \mathrm{t}=1.70, \mathrm{p}=.091)$, age $(\beta=-.09, \mathrm{SE}=0.07, \mathrm{t}=-1.22, \mathrm{p}=.226)$, and the EQ score $(\beta$ $=.08, \mathrm{SE}=0.08, \mathrm{t}=0.93, \mathrm{p}=.355)$ did not. The IRI-EC was also the only significant predictor for the 5-item measure $(\beta=0.22, \mathrm{SE}=0.08, \mathrm{t}=2.64, \mathrm{p}=.009)$, while the other variables were not (gender: $\beta=.15, \mathrm{SE}=0.15, \mathrm{t}=0.99, \mathrm{p}=.325$, age: $\mathrm{b}=-.07, \mathrm{SE}=0.07$, $\mathrm{t}=-1.01, \mathrm{p}=.313$, the EQ score: $\beta=.09, \mathrm{SE}=0.08, \mathrm{t}=1.15, \mathrm{p}=.252$ ). Consistent with the result in Sample 3, religious belief was closely related with the IRI-EC than the EQ. 
Table 1

Descriptive statistics for each sample.

\begin{tabular}{|c|c|c|c|c|c|c|c|c|c|c|c|c|}
\hline & \multicolumn{3}{|c|}{ EQ } & \multicolumn{3}{|c|}{ IRI-EC } & \multicolumn{3}{|c|}{ Religious belief (13-item) } & \multicolumn{3}{|c|}{ Religious belief (5-item) } \\
\hline & $\alpha$ & $M$ & $S D$ & $\alpha$ & $M$ & $S D$ & $\alpha$ & $M$ & $S D$ & $\alpha$ & $M$ & $S D$ \\
\hline \multicolumn{13}{|l|}{ Study 1} \\
\hline Sample $1(N=190)$ & .85 & 18.32 & 7.33 & .77 & 3.47 & 0.62 & .85 & 3.19 & 0.68 & .57 & 3.32 & 0.71 \\
\hline Sample $2(N=152)$ & .84 & 16.35 & 7.16 & .72 & 3.86 & 0.90 & .87 & 2.87 & 0.86 & .39 & 3.02 & 0.74 \\
\hline Sample $3(N=193)$ & .91 & 13.38 & 8.02 & .83 & 3.37 & 0.69 & .92 & 2.96 & 0.85 & .69 & 3.05 & 0.76 \\
\hline Sample $4(N=175)$ & .89 & 14.38 & 7.69 & .85 & 3.35 & 0.81 & .89 & 2.98 & 0.85 & .66 & 3.02 & 0.82 \\
\hline Study $2(N=1319)$ & .89 & 14.90 & 7.72 & .82 & 3.41 & 0.65 & .91 & 3.02 & 0.86 & .69 & 3.10 & 0.80 \\
\hline
\end{tabular}

Table 2

Multiple Linear Regression Analysis Predicting Religious Belief with Gender, Age, the EQ Score, and the IRI-EC Score.

\begin{tabular}{|c|c|c|c|c|c|c|c|c|c|c|c|c|c|c|c|c|}
\hline & \multicolumn{4}{|c|}{ Gender } & \multicolumn{4}{|c|}{ Age } & \multicolumn{4}{|c|}{ EQ } & \multicolumn{4}{|c|}{ IRI-EC } \\
\hline & $\beta$ & $S E$ & $t$ & $p$ & $\beta$ & $S E$ & $t$ & $p$ & $\beta$ & $S E$ & $t$ & $p$ & $\beta$ & $S E$ & $t$ & $p$ \\
\hline \multicolumn{17}{|l|}{ Study 1: Sample 1} \\
\hline 13-item measure & .39 & 0.15 & 2.62 & .010 & .07 & 0.07 & 0.92 & .358 & .04 & 0.07 & 0.47 & .642 & .06 & 0.07 & 0.74 & .462 \\
\hline 5-item measure & .53 & 0.15 & 3.62 & $<.001$ & -.03 & 0.07 & -0.48 & .635 & .01 & 0.07 & 0.16 & .876 & -.01 & 0.07 & -0.09 & .932 \\
\hline \multicolumn{17}{|l|}{ Study 1: Sample 2} \\
\hline 13-item measure & .14 & 0.20 & 0.68 & .498 & -.05 & 0.08 & -0.55 & .580 & .19 & 0.09 & 2.21 & .028 & -.01 & 0.08 & -0.05 & .957 \\
\hline 5-item measure & .26 & 0.20 & 1.28 & .204 & -.06 & 0.08 & -0.75 & .457 & .18 & 0.09 & 2.10 & .038 & .004 & 0.08 & 0.05 & .960 \\
\hline \multicolumn{17}{|l|}{ Study 1: Sample 3} \\
\hline 13-item measure & .28 & 0.16 & 1.75 & .082 & .11 & 0.07 & 1.52 & .131 & .04 & 0.08 & 0.55 & .586 & .30 & 0.08 & 3.98 & $<.001$ \\
\hline 5-item measure & .21 & 0.16 & 1.31 & .194 & .13 & 0.07 & 1.84 & .067 & .06 & 0.08 & 0.75 & .454 & .28 & 0.08 & 3.63 & $<.001$ \\
\hline \multicolumn{17}{|l|}{ Study 1: Sample 4} \\
\hline 13-item measure & .26 & 0.15 & 1.70 & .091 & -.09 & 0.07 & -1.22 & .226 & .08 & 0.08 & 0.93 & .355 & .17 & 0.08 & 1.99 & .049 \\
\hline 5-item measure & .15 & 0.15 & 0.99 & .325 & -.07 & 0.07 & -1.01 & .313 & .09 & 0.08 & 1.15 & .252 & .22 & 0.08 & 2.64 & .009 \\
\hline \multicolumn{17}{|l|}{ Study 2} \\
\hline 13-item measure & .29 & 0.06 & 4.89 & $<.001$ & .01 & 0.03 & 0.17 & .863 & .10 & 0.03 & 3.35 & .001 & .22 & 0.03 & 7.55 & $<.001$ \\
\hline 5-item measure & .20 & 0.06 & 3.45 & .001 & .03 & 0.03 & 1.07 & .286 & .04 & 0.03 & 1.37 & .170 & .25 & 0.03 & 8.55 & $<.001$ \\
\hline
\end{tabular}




\subsection{Mini meta-analysis}

Overall, Study 1 demonstrated that empathy predicted religious belief after controlling for the effect of age and gender. However, there was variability in the relationship between the two measures of empathy and religious belief in Samples 1-4; the EQ was a significant predictor of religious belief in Sample 2, whereas, the IRI-EC was significant in Samples 3 and 4.

Given this variability, a mini meta-analysis was conducted to assess the average effect sizes of the EQ and the IRI-EC scores on the 13-item religious belief measure. First, we assessed the unique effect sizes of both the empathy measures at each survey using semipartial correlation coefficients $\left(r_{\mathrm{sp}}\right)$ that "represent the predictive power of an independent variable from a multiple regression model” (Aloe \& Becker, 2012, p. 278), and computed the summary effect using dmetar package (version 0.0.9000; Harrer, Cuijpers, Furukawa, \& Ebert, 2019). The $r_{\mathrm{sp}}$ of the EQ score was .033, .178, .037, and .068 in Samples 1-4, respectively. Similarly, the $r_{\mathrm{sp}}$ of the IRI-EC score was $.053,-.004, .270$, and .146 .

Figure 1 shows the results of the mini meta-analysis. The random effect model suggested that the summary estimate of $r_{\mathrm{sp}}$ of the EQ was .0740 with $95 \%$ confidence interval (CI) of -.0001 to $.1472(\mathrm{z}=1.96, \mathrm{p}=.0502)$, while that of the IRI-EC was .1203 with $95 \%$ CI of .0002 to $.2370(\mathrm{z}=1.96, \mathrm{p}=.0496)$. That is, both empathy measures had weak effect sizes on religious belief. More importantly, the IRI-EC had a stronger association with religious belief. For further confirmation, we collected another sample of data using these effect sizes to conduct a power analysis. 


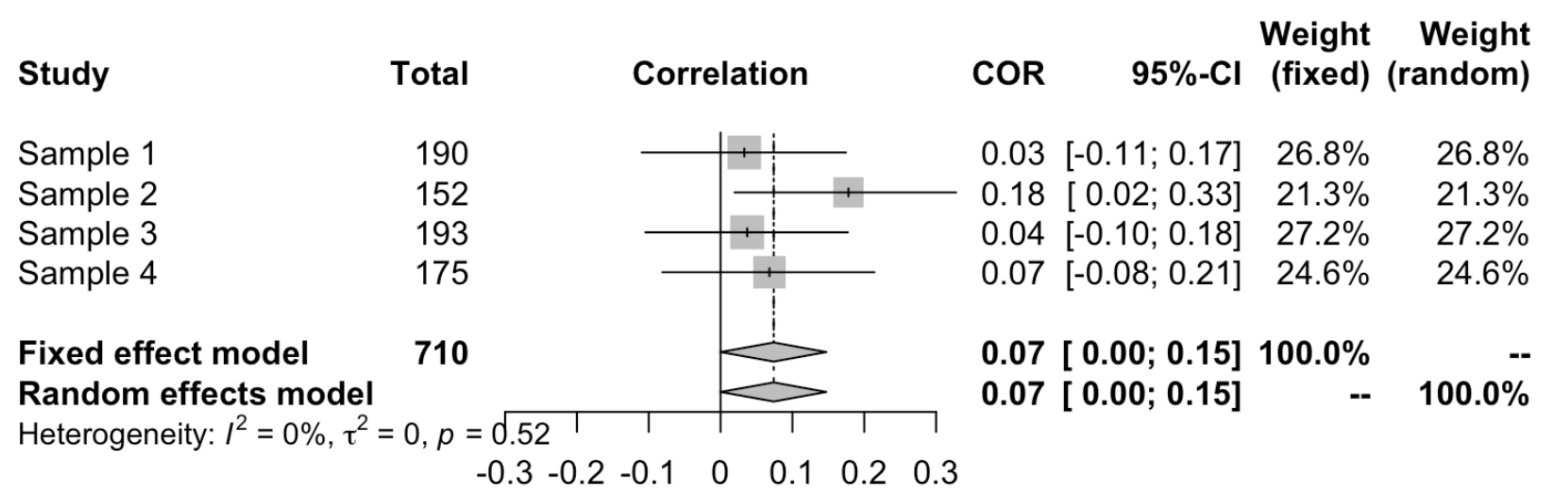

Figure 1. The results of mini meta-analysis for the effect of the EQ on religious belief (13-item)

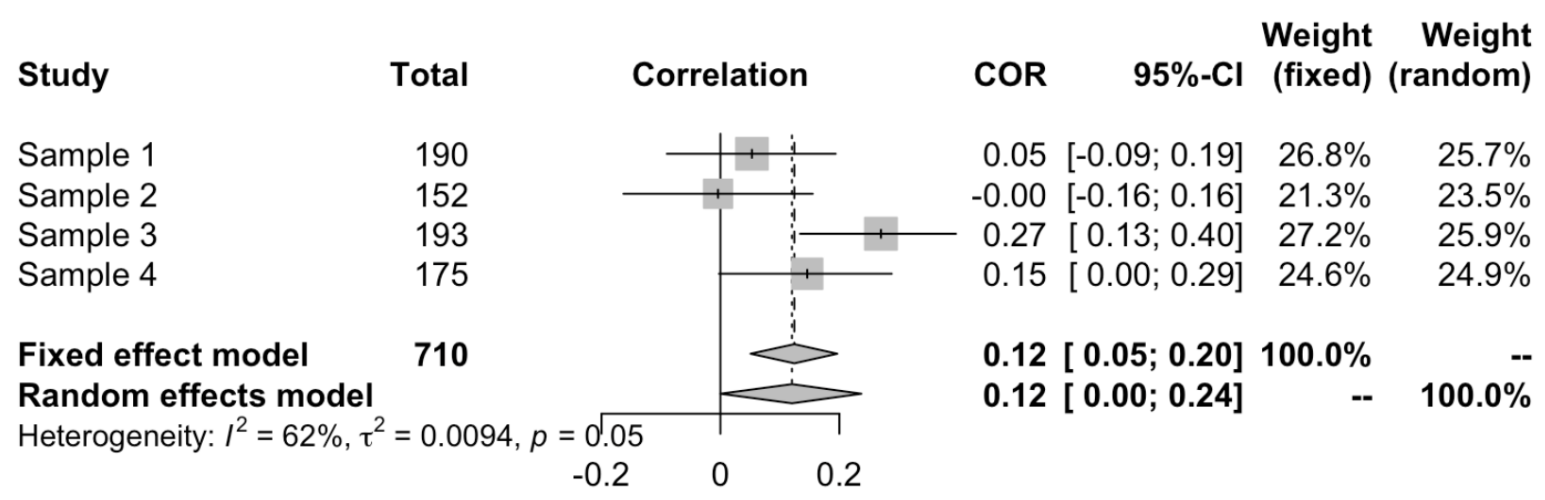

Figure 2. The results of mini meta-analysis for the effect of the IRI-EC on religious belief (13-item) 


\section{Study 2}

Study 2 aimed to confirm the results of Study 1, i.e., the IRI-EC is strongly linked to religious belief than the EQ. We calculated the optimal sample size to detect the relationship between empathy and religious belief, as estimated in the mini meta-analysis, and examined the relationship between the two measures of empathy and religious belief. Study 2 was preregistered at https://osf.io/g89te.

\subsection{Methods}

\subsubsection{Participants}

The power analysis estimated the required sample size as 1431 when $r=.0740$, and 540 when $\mathrm{r}=.1203$. Hence, we decided to recruit 1431 participants through a web survey service (Yahoo! crowdsourcing and goggle form). As a result, 1440 adults $\left(\mathrm{M}_{\mathrm{age}}=48.13\right.$, $\mathrm{SD}_{\text {age }}=10.87,994$ men, 428 women, 18 unknown) participated in this study. We note that there are small differences in the power analysis between Study 2 and its preregistration, specifically the summary estimate of $r_{\mathrm{sp}}$. This is because the sizes of Samples 1-4 in Study 1 decreased after the exclusion criteria was employed (i.e., data from participants whose answers were unreliable had not been excluded in the preregistration), and the estimations were thus adjusted.

\subsubsection{Materials and Procedure}

Materials were the same as Study 1. Participants were given Google Forms to complete the questionnaires in the following order: the demographic questions (age and gender), religious belief measure (13-item: $\alpha=.91, \mathrm{M}=3.02, \mathrm{SD}=0.86,5$-item: $\alpha=.69$, $\mathrm{M}=3.10, \mathrm{SD}=0.80)$, the EQ $(\alpha=.89, \mathrm{M}=14.90, \mathrm{SD}=7.72)$, and the IRI-EC $(\alpha=.82, \mathrm{M}$ $=3.41, \mathrm{SD}=0.65)$ 


\subsection{Results and Discussion}

One hundred and twenty-one participants (8.4\%) were excluded with similar exclusion criteria as Study 1. The 13-item religious belief score was positively correlated with the EQ score $(r=.20, p<.001)$ and the IRI-EC score $(r=.27, p<.001)$. The 5 -item belief score showed a similar correlation with the EQ scores $(r=.15, \mathrm{p}<.001)$ and the IRIEC $(r=.28, p<.001)$. The two measures of empathy were positively correlated with each other $(\mathrm{r}=.41, \mathrm{p}<.001)$.

The same multiple regression model as Study 1 was employed to confirm the results. We note that although this analytic strategy was not identical to the preregistered strategy (i.e., a hierarchical regression), both the strategies were same in their purpose (examining if the IRI-EC is strongly linked to religious belief than the EQ). The analysis showed that the EQ $(\beta=.10, \mathrm{SE}=0.03, \mathrm{t}=3.35, \mathrm{p}=.001)$ and the IRI-EC scores $(\beta=.22, \mathrm{SE}=0.03, \mathrm{t}$ $=7.55, \mathrm{p}<.001)$ were both significant predictors of the 13 -item religious belief score. Gender was also significant $(\beta=.29, \mathrm{SE}=0.06, \mathrm{t}=4.89, \mathrm{p}<.001)$, meaning women showed higher religious belief scores than men. Whereas, age was not significant $(\beta=.01, \mathrm{SE}=$ $0.03, \mathrm{t}=0.17, \mathrm{p}=.863)$. The same analysis with the 5 -item religious belief score as the dependent variable yielded slightly different results: the IRI-EC $(\beta=.25, \mathrm{SE}=0.03, \mathrm{t}=$ $8.55, \mathrm{p}<.001)$ and gender $(\beta=.20, \mathrm{SE}=0.06, \mathrm{t}=3.45, \mathrm{p}=.001)$ significantly predicted religious belief, but age $(\beta=-.09, \mathrm{SE}=0.07, \mathrm{t}=-1.22, \mathrm{p}=.226)$ and the EQ score $(\mathrm{b}=.04$, $\mathrm{SE}=0.03, \mathrm{t}=1.37, \mathrm{p}=.170)$ did not. These results were consistent with the mini metaanalysis; the IRI-EC is strongly linked to religious belief compared to the EQ.

It is important to note the difference between the results of analyses in light of the differences in the religious belief measures. While the 13 -item scale measured broader supernatural beliefs (belief in gods and paranormal belief), the 5-item scale measured only belief in gods. Hence, the results of the analyses in Study 2 suggested that the EQ had no 
significant unique effect on the belief in gods when the IRI-EC was statistically controlled in a multiple linear regression model. In fact, in a model with gender, age, and the EQ score predicting the 5-item religious belief score, the EQ was a significant predictor $(\beta=.27, \mathrm{SE}$ $=0.03, \mathrm{t}=9.91, \mathrm{p}<.001)$ along with gender $(\beta=.21, \mathrm{SE}=0.06, \mathrm{t}=3.56, \mathrm{p}<.001)$. This result was similar to Jack et al. (2016), who found a robust and positive association between the IRI-EC and belief in gods (measured by single item "Do you believe in the existence of either god or a universal spirit?"), but no association between measures of mentalizing (including the EQ) and the belief. Thus, Study 2 successfully replicated these previous findings with a non-WEIRD sample.

\section{General Discussion}

The present study examined the relationship between empathy and religious belief. Based on literature in personality psychology and the cognitive and evolutionary science of religion, we hypothesized that the IRI-EC (i.e., empathic concern) is strongly linked to religious belief than the EQ (i.e., a broader measure of empathy). A mini meta-analysis using the results of four samples (Study 1) and a survey with another large sample (Study 2) confirmed this hypothesis; the IRI-EC was a better predictor of religious belief compared to the EQ, although both measures had their unique effects on religious belief, especially broader supernatural beliefs.

The first contribution of the present study is that we demonstrated the robustness and generalizability of the link between empathy and religiosity. Although previous studies have shown this relationship, they did so with mostly Western samples (e.g., Jack et al., 2016; Lindeman et al., 2015; Łowicki \& Zajenkowski, 2017; Norenzayan et al., 2012; Routledge et al., 2017; Willard \& Norenzayan, 2013). A few studies have been conducted with samples from other cultures (Islamic: Khan et al., 2005; Japanese: Ishii, 2017). The 
present study demonstrated the same relationship in large samples of Japanese undergraduates and non-student adults (i.e., non-WEIRD sample). Interestingly, people in Japan naively believe in supernatural agents, although Japan is known as a less religious country (e.g., Kavanagh, \& Jong, 2020; Staufenberg, 2016). Therefore, our findings strongly suggested that the relationship between empathy and religious belief is not conditional on religious faith. Thus, suggesting that findings in personality psychology about this relationship are culturally independent.

The current study also contributed to extending the discussion about psychological foundations of religious belief by showing the close relationship between religious belief and other-oriented aspect of empathy, that is, empathic concern. The early works in the cognitive science of religion have theorized that the key for the emergence of religious belief is to perceive supernatural agents as human-like agents (e.g., Barrett, 2000; Barrett \& Keil, 1996). Subsequent studies assumed that our social cognitive ability such as agent detection (i.e., hyper-active agent detective device) or mentalizing allows us to do so and also demonstrated that the measures of such ability are linked to religious belief (e.g., Gervais, 2013; Norenzayan \& Gervais, 2013, for reviews). Especially, the EQ has been considered as a good measure of such a socio-cognitive ability (e.g., Norenzayan et al., 2012; Lindeman et al., 2015; Willard \& Norenzayan, 2013) based on works of Baron-Cohen (e.g., Baron-Cohen, \& Wheelwright, 2004), who argued that people with autism disorder spectrum tend to lack the ability to attribute mental states to others and subsequently developed the EQ to measure this tendency. The current study showed that empathic concern, measured by the IRI-EC, was a better predictor of religious belief than the EQ. As mentioned, empathic concern is other-oriented feelings of sympathy and concern for unfortunate others (Davis, 1983). To have such feelings, people must first have the ability to attribute mental states to others. Hence, mentalizing may be insufficient to believe in 
supernatural agents, but empathic concern plays an essential role in developing the belief. This idea is reasonable because people with high empathic concern may care more about and pay more attention to the mental states of spiritual agents, which would lead people to feel closer to such agents, and even have imaginary interactions with them, consequently, strengthening their belief in supernatural agents. In other words, our findings suggest that although perceiving supernatural agents with human-like attributes gives a foundation for developing religious belief, motivation to interact with such agents further facilitates the belief.

Some limitations of the current work should be acknowledged. First, our data were correlational. Even though we argued the possibility that empathic concern may be crucial for forming a religious belief, we could not test this possibility directly. Many previous studies have also employed a correlational method similar to our study or employed quasiexperimental designs (e.g., comparing those who have empathy and those not) because empathy is a personality trait and is difficult to manipulate. In future, we need better methodological designs that overcome this limitation. For example, a longitudinal study that tracks developmental changes in empathy and religious belief.

Second, we employed self-report measures to evaluate individual differences in empathy and religious belief. Even though self-report measures are a useful tool in psychological studies, social desirability may affect the responses. This may especially be the case for the current study as empathic concern and religious belief may involve moral connotations for some people (e.g., to sympathize and be concerned for others' misery are morally good in general, so is to respect gods). Thus, the correlation between empathy and religious could be a spurious correlation caused by social desirability. Studies using physiological and behavioral responses (e.g., the Implicit Association Test of religious belief, Jong, Halberstadt, \& Bluemke, 2012) would better elucidate this relationship. 
These shortcomings notwithstanding, the current work provides reliable evidence of the close link between empathy and religious belief in non-WEIRD samples. Our work also underscores the possibility that empathic concern plays an essential role in developing religious belief.

\section{Acknowledgements}

We would like to thank Editage [http://www.editage.com] for editing and reviewing this manuscript for English language. 


\section{References}

Aghababaei, N., Mohammadtabar, S., \& Saffarinia, M. (2014). Dirty Dozen vs. the H factor: Comparison of the Dark Triad and Honesty-Humility in prosociality, religiosity, and happiness. Personality and Individual Differences, 67, 6-10. https://doi.org/10.1016/j.paid.2014.03.026

Apperly, I. A. (2012). What is "theory of mind"? Concepts, cognitive processes and individual differences. The Quarterly Journal of Experimental Psychology, 65(5), 825-839. https://doi.org/10.1080/17470218.2012.676055

Baron-Cohen, S., \& Wheelwright, S. (2004). The Empathy Quotient: An investigation of adults with Asperger Syndrome or High Functioning Autism, and normal sex differences. Journal of Autism and Developmental Disorders, 34(2), 163-175. https://doi.org/10.1023/b:jadd.0000022607.19833.00

Barrett, J. L. (2000). Exploring the natural foundations of religion. Trends in Cognitive Sciences, 4(1), 29-34. https://doi.org/10.1016/s1364-6613(99)01419-9

Barrett, J. L., \& Keil, F. C. (1996). Conceptualizing a Nonnatural Entity: Anthropomorphism in God Concepts. Cognitive Psychology, 31(3), 219-247. https://doi.org/10.1006/cogp.1996.0017

Davis, M. H. (1983). Measuring individual differences in empathy: Evidence for a multidimensional approach. Journal of Personality and Social Psychology, 44(1), 113-126. https://doi.org/10.1037/0022-3514.44.1.113

Ebert, T., Gebauer, J. E., Talman, J. R., \& Rentfrow, P. J. (2020). Religious people only live longer in religious cultural contexts: A gravestone analysis. Journal of Personality and Social Psychology, 119(1), 1-6. https://doi.org/10.1037/pspa0000187 
Eysenck, H. J. (1975). The structure of social attitudes. British Journal of Social and Clinical Psychology, 14(4), 323-331. https://doi.org/10.1111/j.20448260.1975.tb00188.x

Eysenck, H. J. (1976). Structure of social attitudes. Psychological Reports, 39(2), 463-466. https://doi.org/10.2466/pr0.1976.39.2.463

Eysenck, M. W. (1998). Personality and the psychology of religion. Mental Health, Religion \& Culture, 1(1), 11-19. https://doi.org/10.1080/13674679808406493

Fincher, C. L., \& Thornhill, R. (2012). Parasite-stress promotes in-group assortative sociality: The cases of strong family ties and heightened religiosity. Behavioral and Brain Sciences, 35(2), 61-79. https://doi.org/10.1017/s0140525x11000021

Francis, L. J., \& Katz, Y. J. (1992). The relationship between personality and religiosity in an Israeli sample. Journal for the Scientific Study of Religion, 31(2), 153. https://doi.org/10.2307/1387005

Gervais, W. M. (2013). Perceiving Minds and Gods. Perspectives on Psychological Science, 8(4), 380-394. https://doi.org/10.1177/1745691613489836

Haddad, B., Angman, M., Archer, T., \& Garcia, D. (2016). Dark triad, sociosexual orientation and religious affiliation: An association and moderation study. Clinical and Experimental Psychology, 2(2). https://doi.org/10.4172/2471-2701.1000124

Harrer, M., Cuijpers, P., Furukawa, T. \& Ebert, D. D. (2019). dmetar: Companion R Package For The Guide 'Doing Meta-Analysis in R'. R package version 0.0.9000. URL http://dmetar.protectlab.org/.

Heider, F., \& Simmel, M. (1944). An experimental study of apparent behavior. The American Journal of Psychology, 57(2), 243. https://doi.org/10.2307/1416950

Himichi, T., Osanai, H., Goto, T., Fujita, H., Kawamura, Y., Davis, M. H., \& Nomura, M. (2017). Development of a Japanese version of the Interpersonal Reactivity Index. 
The Japanese Journal of Psychology, 88(1), 61-71. https://doi.org/10.4992/jjpsy.88.15218 (in Japanese with English abstract)

Ikeuchi, H. (2010). Animistic thinking in adults: The memorial service for dolls as a voluntary loss. Japanese Journal of Social Psychology, 25(3), 167-177, https://doi.org/10.14966/jssp.KJ00006203282 (in Japanese with English abstract)

Ishii, T. (2017). Mentalizing, but not autistic traits, predicts religious belief in a sample of healthy Japanese youth. Letters on Evolutionary Behavioral Science, 8(2), 32-35. https://doi.org/10.5178/lebs.2017.61

Jack, A. I., Friedman, J. P., Boyatzis, R. E., \& Taylor, S. N. (2016). Why do you believe in God? Relationships between religious belief, analytic thinking, mentalizing and moral concern. PLOS ONE, 11(3), e0149989. https://doi.org/10.1371/journal.pone.0149989

Jonason, P. K., \& Kroll, C. H. (2015). A Multidimensional view of the relationship between empathy and the dark triad. Journal of Individual Differences, 36(3), 150-156. https://doi.org/10.1027/1614-0001/a000166

Jong, J., Halberstadt, J., \& Bluemke, M. (2012). Foxhole atheism, revisited: The effects of mortality salience on explicit and implicit religious belief. Journal of Experimental Social Psychology, 48(5), 983-989. https://doi.org/10.1016/j.jesp.2012.03.005

Jong, J., Bluemke, M., \& Halberstadt, J. (2013). Fear of death and supernatural beliefs: Developing a new Supernatural Belief Scale to test the relationship. European Journal of Personality, 27(5), 495-506. https://doi.org/10.1002/per.1898

Kavanagh, C. M., \& Jong, J. (2020). Is Japan religious? Journal for the Study of Religion, Nature and Culture, 14(1), 152-180. https://doi.org/10.1558/jsrnc.39187 
Khan, Z. H., Watson, P. J., \& Habib, F. (2005). Muslim attitudes toward religion, religious orientation and empathy among Pakistanis. Mental Health, Religion \& Culture, 8(1), 49-61. https://doi.org/10.1080/13674670410001666606

Lilienfeld, S. O., Latzman, R. D., Watts, A. L., Smith, S. F., \& Dutton, K. (2014). Correlates of psychopathic personality traits in everyday life: Results from a large community survey. Frontiers in Psychology, 5, 740. https://doi.org/10.3389/fpsyg.2014.00740

Lindeman, M., Svedholm-Häkkinen, A. M., \& Lipsanen, J. (2015). Ontological confusions but not mentalizing abilities predict religious belief, paranormal belief, and belief in supernatural purpose. Cognition, 134, 63-76. https://doi.org/10.1016/j.cognition.2014.09.008

Łowicki, P., \& Zajenkowski, M. (2017). No empathy for people nor for God: The relationship between the Dark Triad, religiosity and empathy. Personality and Individual Differences, 115, 169-173. https://doi.org/10.1016/j.paid.2016.02.012

Norenzayan, A., \& Gervais, W. M. (2013). The origins of religious disbelief. Trends in Cognitive Sciences, 17(1), 20-25. https://doi.org/10.1016/j.tics.2012.11.006

Norenzayan, A., Gervais, W. M., \& Trzesniewski, K. H. (2012). Mentalizing deficits constrain belief in a personal God. PLoS ONE, 7(5), e36880. https://doi.org/10.1371/journal.pone.0036880

Norenzayan, A., Shariff, A. F., Gervais, W. M., Willard, A. K., McNamara, R. A., Slingerland, E., \& Henrich, J. (2016). The cultural evolution of prosocial religions. Behavioral Brain Sciences, 39, e1. https://doi.org/10.1017/s0140525x14001356 
Premack, D., \& Woodruff, G. (1978). Does the chimpanzee have a theory of mind? Behavioral and Brain Sciences, 1(4), 515-526. https://doi.org/10.1017/s0140525x00076512

Routledge, C., Roylance, C., \& Abeyta, A. A. (2017). Further exploring the link between religion and existential health: The effects of religiosity and trait differences in mentalizing on indicators of meaning in life. Journal of Religion and Health, 56(2), 604-613. https://doi.org/10.1007/s10943-016-0274-z

Sakata, H., Kawakami, M., \& Koshiro, E. (2012). Constructing attitudes towards paranormal phenomena scale (APPle) short edition (1): Attitudes towards paranormal phenomena (29). The 76th annual convention of the Japanese Psychological Association, 238 (in Japanese).

Staufenberg, J. (2016). 'The Six Countries in the World That Believe in God the Least', The Independent, 23 March. Online: http://www.independent.co.uk/ news/uk/atheists-countries-list-six-world-most-convinced-a6946291.html.

Steger, M. F., \& Frazier, P. (2005). Meaning in life: One link in the chain from religiousness to well-being. Journal of Counseling Psychology, 52(4), 574-582. https://doi.org/10.1037/0022-0167.52.4.574

Terrizzi Jr, J. A., Shook, N. J., \& Ventis, W. L. (2012). Religious conservatism: an evolutionarily evoked disease-avoidance strategy. Religion, Brain \& Behavior, 2(2), 105-120. https://doi.org/10.1080/2153599x.2012.695514

Wakabayashi, A., Baron-Cohen, S., \& Wheelwright, S. (2006). Individual and gender differences in empathizing and systemizing: measurement of individual differences by the Empathy Quotient (EQ) and the Systemizing Quotient (SQ). The Japanese Journal of Psychology, 77(3), 271-277, https://doi.org/10.4992/jjpsy.77.271 (in Japanese with English abstract) 
Wakabayashi, A., Baron-Cohen, S., Wheelwright, S., Goldenfeld, N., Delaney, J., Fine, D., ... Weil, L. (2006). Development of short forms of the Empathy Quotient (EQShort) and the Systemizing Quotient (SQ-Short). Personality and Individual Differences, 41(5), 929-940. https://doi.org/10.1016/j.paid.2006.03.017

White, J., Joseph, S., \& Neil, A. (1995). Religiosity, psychoticism, and schizotypal traits. Personality and Individual Differences, 19(6), 847-851. https://doi.org/10.1016/s0191-8869(95)00129-8

Wilde, A., \& Joseph, S. (1997). Religiosity and personality in a Moslem context. Personality and Individual Differences, 23(5), 899-900. https://doi.org/10.1016/s0191-8869(97)00098-6

Willard, A. K., \& Norenzayan, A. (2013). Cognitive biases explain religious belief, paranormal belief, and belief in life's purpose. Cognition, 129(2), 379-391. https://doi.org/10.1016/j.cognition.2013.07.016

Williams, E., \& Francis, L. J. (2006). Personality and attitude toward Christianity among Churchgoers: A replication. Psychological Reports, 99(1), 292-294. https://doi.org/10.2466/pr0.99.1.292-294 